\title{
Angular Gyrus
}

National Cancer Institute

\section{Source}

National Cancer Institute. Angular Gyrus. NCI Thesaurus. Code C32077.

The portion of the brain located in the parietal lobe that plays a role in intersensory processing, language comprehension, and cognition. 